\title{
Иван Ахметьев
}

\section{Миниатюры}

\author{
Сборник стихов
}

Verlag Otto Sagner München · Berlin - Washington D.C.

Digitalisiert im Rahmen der Kooperation mit dem DFG-Projekt „Digi20“

der Bayerischen Staatsbibliothek, München. OCR-Bearbeitung und Erstellung des eBooks durch den Verlag Otto Sagner:

http://verlag.kubon-sagner.de

() bei Verlag Otto Sagner. Eine Verwertung oder Weitergabe der Texte und Abbildungen, insbesondere durch Vervielfältigung, ist ohne vorherige schriftliche Genehmigung des Verlages unzulässig.

«Verlag Otto Sagner» ist ein Imprint der Kubon \& Sagner Gmb|Hen Achmet'ev - 9783954794386 


\section{ARBEITEN UND TEXTE ZUR SLAVISTIK $\cdot 47$ HERAUSGEGEBEN VON WOLFGANG KASACK}

\section{Иван Ахметьев}

\section{Миниаторы}

Cборнак стихов

Предисловне Всеволода Некрасова

$$
1990
$$

München . Verlag Otto Sagner in Kommission 
Der Moskauer Lyriker Ivan Alekseevič Achmet'ev, geb. 31.5.1950 legt mit diesen "Miniaturen" seinen ersten Lyrikband vor. Ihn empfehlen Vsevolod Nekrasov, also einer der führenden Vertreter der Zweiten Kultur, die vor allem aus formalen Gründen bis zur Perestroika die Menschen in der Sowjetunion nicht erreichen konnten und Nina Sadur als eine stark im Geistigen wurzelnde Dramatikerin. Diese Namen bestimmen Achmet'evs Platz in der russischen Literatur, deren Vielfalt mit der Veröffentlichung dokumentiert wird. (Der Titel des Buches stammt vom Herausgeber)

"Миниаторы" - это первыи сборник стихов московского поэта Ивана Алексеевича Ахметьева (род. 315.1950 г.). Его рекомендуют поэт Всеволод Нехрасов, один из ведуиих представителеи Второи культуры, на которьх распространялась до перестроики прежде всего эстетическая цензура и драматург Нина Садур, пьесы которои проникнуты глубокои духовностью и дошли до зрителя также только при перестроике. Эти имена определяют место Ахметьева в русскои литературе, многообразие которои документируется этим изданием. (Заглавие книти от издателя).

W.K.

Aayerische
Staatsbibliothek
München

Alle Rechte vorbehalten

ISSN 0173-2307

ISBN 3-87690-375-0

Gesamtherstellung Walter Kleikamp · Köln

Printed in Germany 


\section{П Р Е ДИ С Л О В И Е}

Если впрямь начинать, как положено, с родников и истоков, то стихи Ахметъева, по-моему, скореи похожи на какие-то точки конденсации влаги: они максимально автономны, прежде всего не связаны ни с какои, ни с чьеи системои - системои подачи и распределения. Нет того, чтобы открыть кран - и пошло беспрепятственное словоизлияние. Нет и нет тут случай в корне обратный. "Духовность - / То есть / Недоверчивость". Беспрепятственному-то словоизлиянию, стихописанию, рифмованному ли, "свободному" и не доверяет прежде всего Ахметьев. "Я, правда, так не умею. / Но я и не знаю, / Зачем это нужно..." Не доверяет, и у него естъ основания - опыт, знакомыи каждому из нас как нельзя лучше. Хотя почему же "как нельзя"?.. В том-то и дело, что можно, оказывается. А может быть - и необходимо.

Нам знакомо - в смысле - мы учитываем, корректируем. Нам известно в общем и целом, что источники-таки под сомнением: еще вчера говорилось, что ленинградцам подают чистейую в мире 
ладожскую воду, как москвичам - мытищинскую. Родник, конечно, не кран - но мы же видим, как водопровод претендует быть родником, а трубам лет 70, и грани между водопроводом и канализацией они всё условней, да и родников всё меньше, а что остались - из тои же земли со всеми её нитритами и нитратами... Всё это мы знаем, берем в соображение по крайнеи мере пытаемся, но всё-таки вначале для нас было слово, а потом уже допущено было известное в нём сомнение, мы берём слово и берём некоторую поправку...

Так вот Ахметьев не берёт ничего готового. Ето отучили с самого начала, может быть, ещё до рождения - как собак отучают перченой приманкой.

Или, если сказать "берёт", то не хватает в пасть, а недоумевает, обследует так и эдак. Пытается освоить на глазах. Кстати, это и интересно...

А в общем, он тем и взял, что не берёт. Не берёт, а порождает. Не знает - было слово, не было слова, пока оно само не возникает в нём и из него не выскакивает, и тут оно узнается - стало быть да, всё-таки слово было. И опять есть. Какое есть - вот оно.

Всеволод Некрасов 
слёзы высыхают

ветер стихает

$$
\text { *** }
$$

неподвижность

часовои стрелки

***

синее пальто

серое лицо

* * *

груз поступков

груз ошибок

груз впечатлении

тяжелит мою голову

она велика

но компактна 


$$
\text { * * * }
$$

искусственные ёлки хороши

вот только жаль

что они не осыпаются

$$
* * *
$$

\section{иди}

путём обид

$$
\text { *** }
$$

за окном моим черно

не жалеите чёрнои краски

$$
\text { * * * }
$$

\section{добро сильней}

но я устал

и рифму не могу наити

$\boldsymbol{h}$ не могу уснуть 
под взглядом испытателя упорным разладился вселенский механизм

***

прия тно

pукy

положить на стол

***

куда нам спешить

спешить нам некуда

я никогда не спешу

***

прошу прошения

вас $и$ так много

а тут еще $я$ 
Я выключил свет

на этом кончился день

$* * *$

M.

BOT

и пой свою

серуго песнго

$$
\text { *** }
$$

M.

музыка

уносящая в счастье

и я смотрю $\boldsymbol{B}$

OKHO

нужно ли больше

$$
\text { *** }
$$

кувшин воды

И возможность уйти 
история нас рассудит

если она ещё будет

$$
\text { *** }
$$

музыка

родина моя

$$
\text { *** }
$$

Европа двумя войнами

насильственно привязала нас

к своему ритму

что ещё сказать - не знаю

$$
\text { * * * }
$$

глядеть глядеть

на падающй снег 
приити к женщине поговорить о чувствах

$$
* * *
$$

вид у нас унылый

мы наклоняем голову

и вытягиваем шею

как будто ждём

удара топора

$$
* * *
$$

сердце торопит меня

я устало я устало

думап cкореe

$$
* * *
$$

вечер

смотрю немые фильмы

в окнах противоположного дома 


$$
\text { * * * }
$$

\section{Я выдох}

ты вдох

$$
\text { * * * }
$$

окна окна

и в каждом

хочется пожить

***

словно наверху

облако преставилось

скрылось на лету

$$
\text { * * * }
$$

еле еле

поимал $я$ свою душу

когда она убегала

вниз по течению

струящетося своего

cHa 
nозор позор

co всех сторон

у меня на уме

притворство

***

посмотришь на звёзды пойдешь не спеша

***

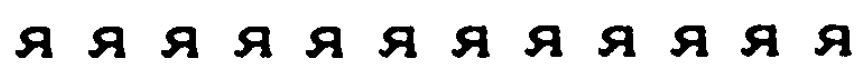

$\begin{array}{llllllllllll}\mathbf{T} & \mathbf{T} & \mathbf{T} & \mathbf{T} & \mathbf{T} & \mathbf{T} & \mathbf{T} & \mathbf{T} & \mathbf{T} & \mathbf{T} & \mathbf{T} & \mathbf{T}\end{array}$

ы ы ы ы ы ы ы ы ы ы ы ы

$\begin{array}{llllllllllll}\mathbf{T} & \mathbf{T} & \mathbf{T} & \mathbf{T} & \mathbf{T} & \mathbf{T} & \mathbf{T} & \mathbf{T} & \mathbf{T} & \mathbf{T} & \mathbf{T} & \mathbf{T}\end{array}$

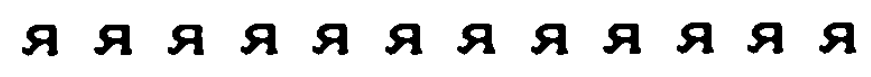

ы ы ы ы ы ы ы ы ы ы ы ы

14 


\section{И ПОМни}

нельзя им показывать

что ты слишком сильно

хочешь на волю

$$
* * *
$$

наверно я псих

не люблю

советской власти

$$
* * *
$$

ходить смотря по сторонам

не посчастливилось ли вам

идёш и песенку поёшь

на беззаботного похож

$$
\text { *** }
$$

когда я только и умел

что управлять струикои мочи 
когда я жду

я уже не жду

и как бы не нуждаюсь

дождаться

- так и дожидаюсь

$$
\text { *** }
$$

ЭХ вы

перевёртыватели

"кто был никем
тот станет всем"

себя переверните

***

Дяди, тёти

Всё вы врете 


\section{дым впереди}

вокруг и слева

и наверху и сзади дым

и если вам по нраву слово

его не раз мы повторим

$$
* * *
$$

мне кажется

я в чем-то здесь

заблуждаюсь

в чем-То

самом главном

во всем

$$
* * *
$$

сколько

здесь мы не были вместе

лет десять?

- нет

девя ть лет 
теперь вам уже не понять

не угадать

не представить

как это было -

To

чего никогда не было

ах, оставь пожалуиста

$\boldsymbol{A}$ сплю

а тебя здесь нет

***

пауза

которую я сделаю

прежде чем ответить

скажет вам больше

$$
\text { *** }
$$

\section{Высохли глаза}

и перестала болеть голова

18 


\section{А я всего лишь \\ поставил под сомнение \\ даже не то что \\ нашёл выход \\ а нащупал корень}

обида на мир

мысль

ч то мне плохо

а $я$ этого не заслуживаю

и не чтобы заслуживал

нет

а это порочныи круг

***

ак туально поворотный пункт

ежемгновенен 
отсюда вытекает бесповоротная беззаботность

но это крайности

так что приходится

и трудиться

и забототься

$$
* * *
$$

погружаясь в воспоминания

я вижу

как много было необыкновенного

значительного

далеко превосходящего

скромные масштабы

моей личности

$$
* * *
$$

духовность

то есть

недоверчивость 
труд создал

из человека обезьяну

из обезьяны - мышку

из мышки - лягушку

из лягушки - рыбку

из рыбки - губку

из губки - туфельку

а туфелька

трудилась-трудилась

и прохудилась

$$
\text { *** }
$$

И силлабическии

и силлабо-тоническии

и акцентныи

неравнометрическия

и унылый

гекзаме трический

и тоскливыи

верлибрическии

и вертикальный

иероглифическии 
и обратныи

арудический

и изустныи

каннибалический

и машинный

кибернетическии

и обычныа

человеческии

$* * *$

выполнили -

перевыполнили

исполнили -

переисполнили

переполнили

преисподнюю

***

радость приходит нечаянно

наше дело

наити для печали предлог

22 
умныи ближе мудрого добрый ближе святого

***

а вы уверены

ч TO вы

Именно это

хотели сказать

?

***

He

"что делать?"

а как достичь состояния

когда это ясно

/для этого надо

ничего не делать/ 


$$
\text { * * * }
$$

больше всего увидишь если замрешь на одном месте

на зиму

лето

ночь

день

как старыи чемодан на балконе

***

эта наша гордость

всегда будет напоминать нам

о нашем позоре

$$
* * *
$$

Вот $\mathrm{Mb}$

и дали миру

великого борца

за мир 
сосуществование

со существом

сосуцим кровь

***

ЧтО ВЫ Что ВЫ

я ничего

$* * *$

когда

когда ты утомишься

когда ты переутомишься

когда ты к Богу обратишься

тогда ты многое поимёшь

когда ты сердцем просветишься

когда от злости исцелишься

тогда ты воссоединишься

тогда тогда ты отдохнёшь 
* * *

\section{ГРАДАЦИЯ}

милиционеров мы не любим и боимся

гебистов - только боимся ***

дело же не в этом было бы что рифмовать

а если есть что рифмовать то можно не рифмовать

$$
* * *
$$

- ну окно здесь для рифмы как ты не понимаешь

- а что не для рифмы?

- ничего не для рифмы.

26 
такие стихи заразительные

даже их не только

запоминаешь

но и сам

сочинять начинаешь

* * *

с самого начала

ни хрена радостного

***

Я так думаю.

Своё мнение я хотел бы

изложить в стихах

Они перед вами. 


$$
\text { *** }
$$

Бог простит

Бог отмстит

$$
\text { * * * }
$$

они мне начинают объяснять

что у него $к$ чему

И довольно нудно

ну зачем мне это нужно?

$$
\text { *** }
$$

\section{ищешь}

осмысленного мира

хочешь

и находишь

/у Севы Некрасова/ 


$$
* * *
$$

Всеволод

всем

BceM

всеM

владеет миром

как Владимир

или Велимир

***

... прописка в г. Москве

Mockва he $\Gamma$.

*** $*$

наверно у многих

и глупых и умных

бывают моменты

бывают минуты

бывают мгновенья

любви постиженья 
бывают часы

созерцанья красы

бывают денечки

бывают деньки

горячие ночки

звоночки гудки

и целые сутки

отсутствия чувств

и целые месяцы

в лоне искусств

и целая вечность

И вся бесконечность

бывает у многих

бывает у всех

$* * *$

лобзай меня

твои лобзанья

мне слаще мира

и войны

30 
//войы и мира

отцов и детей

мёртвых душ

и бедных людеи//

$$
\text { * * * }
$$

скажи

своё УЖО

и бежи

$$
* * *
$$

этот мир вокруг

почта-автомат

еду целыи час

вот они глядят

белые штаны

красные штаны

милиционер

школьникам пример

девочки идут

лапочки уже

мимо прохожу 
в сторону гляжу

нет ли там чего

чтобы посмотреть

чтобы позабыть

чудное лицо

видел я вчера

прелести полна

юность иногда

что еще сказать

право я не зна

может помолчать

или что-нибудь

небо и земля

вышки провода

курсом коммунизм

кроики и шитья

лампочки горят

тут ещё не спят

новый поворот

сердие через раз

завтра и вчера

вот он сладкии миг

больше никогда

что-нибудь всегда 


\section{полежу}

почему

nолежу

подумаю

почему

*** $*$

\section{правильно}

воспи танный

человек

незнаком

с угрызениями

совести

\section{а иной человек}

*ивёт

и его совесть

грызёт

и он пьёт 
и она его грызёт

и он пуще пьёт

и она его пуще

грызёт

и он уже не живуции

а пьющии

всё пуще и пуще

пропащии

$* * *$

на небе

что-то происходит

и что-то происходит

в поле

в лесу

на речке

на природе

на воле

в холоде

и в холе

разная погода

а я всё время дома 
бывает легко

бывает $и$

очень тяжело

***

Кот в мешке

вещь в себе

***

почему

так получается

знают

вышестоящие

товарищи

***

были попытки

которые

не получив развития

превратились в события 


\section{Олегу Васильеву}

взглянем радостно на мир

(мы иначе не умеем)
вот гимнастка на обложке
огонек такои журнал
приподняв немного ножку
балансирует строина
в пятьдесят шестом году
у народа на виду

свет и тьма

свет в домах

снаружи тьма

свет во тьMе

это мы

ЭTO Cвет

а тьмы

HeT 
ои да как тебе не стыдно

ничего кругом не видно

только ты один торчишь

мне показывая шиш

***

камни существуют

деревья растут

звери живые

я думаю

Gor ecrb

$$
* * *
$$

отдельные мои произведения

не представляют собой

ничего особенного

моё творчество в целом

есть портрет

заурядного человека 
эти ещё сношаются

а те yжe на сносях

/тут можно было бы пофилософствовать привести социологические выкладки

а затем

перейи к личным впечатлениям/

$* * *$

возле помойки

после попойи

$* * *$

Hе ищите в его лице

особого злодеиства

эroro heт

он был обычным человеком

отдавал приказы

подписывал бумаги

проводил совещания

38 
/последнее слово за ним

и все ждали

что он скажет/

отмечал праздники

в кругу товарищей по работе

но и боялся

испытывал гнев

раздражение

не всегда мог сдержать

мстительное чувство

и болезненную подозрительность

недалёкий

плутоватыи

он был не лучше

и не хуже окружающих

за это они его и любили

$* * *$

я додумался

смерть избавит от забот

стало полегче 


\section{он любит}

и хочет как лучше

$$
\text { * * * }
$$

конечно

что Я за поэт

моих стихов почти что нет

Быть можно без стихов поэтоМ

И со стихами идиотоМ

nоэтому $я$

не страдан о том

** * $*$

Mожет $я$ плохой отец

никуда не годныи муж

может я вообще подлец

yж

40 


\begin{abstract}
*** $*$
мои стихи рассчитаны

на максимально чуткого

и максимально доброжелательного

читателя
\end{abstract}

такого читателя

они создают

***

я обязан указать

сколь многим я обязан

вам и вашим указаниям

о моих обязанностях

***

полу помаленьку

полу сам по ceбe

полу за компанию 


\section{Б.}

мы не повздорили поспорили

и не рассорились

а лишь

во взглядах разошлись

$$
\text { *** }
$$

вот и пасха

прошла

мимо церкви

проезжан

те же кресты

кругом ея

тот же автобус

Tot жंe $я$ 
$\mathrm{He}$

у нас тут

за разговоры не убивают

при начальстве

конечно

все молчат

но и так

между собои

болтунов мы не уважаем

умный

как говорится

помалкивает

вы спросите

"а зачем тогда ум"

а вот чтобы чувствовать

градации

это нельзя назвать этикет

скорее инстинкт 
болезнь к смерти

и смерть как выздоровление

даa

скользкая жизнь

можно сказать

сама себе награда

одна надежда на Бога

потому что

как ни стараися

в лучшем случае помрешь

в худшем выживешь

И это не упадочные настроения

а объективная реальность

мироощущения

определяемого бытиём

иногда

с непоня тною целью

между собой заговаривают

незнакомые люди

и выясняется

44 
штатное расписание расписание поездов график отпусков сеть политпросвещения комитет народного контроля струк тура руководящих органов система распределения услуг номенклатурныя работник персональная пенсия подоходныи налот спецсписок совершенно секретно для служебного пользования тарифная сетка

участок $N$ - / " :, . ? 子 ! артикул $12 \% 456789$ b = в строгих рамках в чётких пределах

в плановом порядке в порядке живой очереди 


\section{с исключением}

длЯ Инвалидов

ветеранов

членов семеи героев

и серьёзнодушевнобольных

по пути следования

по особому распоряжению

минута молчания

скорбная весть

совесть И честь

местные онганы власти и чести

в бутылку не лезьте

здрась те

ходынскии мемориал

лубянский микроцефал

люблянскии чемпионат

любимовский театр

отделение милиции

паспортный стол

столп соцреализма

бездна комизма

прорва маразма 
остатки

огарки

ошмётки

очёски

Очистки

обломки

обноски

оглядки

опаски

оговорки

***

может быть

мы многого не знаем

a может 6 ыть

мы не знаем

ничего существенного

$* * *$

даже лень

написать это слово

c $о$ з н $\mathrm{H}$ и $\mathrm{e}$ 
и из каких оно состоит

как говорится

дырок

*** $*$

скрывает всё то

что для нас

к сожалению

нужно в самом деле

(и просит прощения)

* * *

я правда

так не умею

но $\boldsymbol{я} И$

не понимаю

зачем это надо

48 
у меня есть

около сотни крючков

которыми я цепляюсь за жизнь

и некоторые из них всегда

попадают не туда

* * *

если верить нашим чувствам

если верить нашим словам

$$
* * *
$$

продуманность

придаёт дейстию

оттенок одухотворённости

и даёт

удовле творение 


$$
\text { * * * }
$$

ты попытался вместить две противоположности и

не сумев их примирить раздвоился сам

$$
\text { *** }
$$

остальное время

я мучительно отсутствую

$$
* * *
$$

да уж ладно

да уж поздно

$$
* * *
$$

Отчего она такая

ваша Haташа

добрая хорошая

50 
Я $\boldsymbol{\aleph}$ Этому

не готов

$$
\text { * * * }
$$

месяц тоненький-тоненький

старенький

$* * *$

4 Tо-то есть во мне

что верит

c"час мне кажется

чTO ECTB

/ запишу

a то забуду/

* * *

по одной причине

было тошно 
по другой - грустно

и по трём - одиноко

может, Я недостоин

или не так устроен?

***

правильно ли вы

меня понимаете?

/даже правильнее меня/

/даже правильнее себя/

***

- а жизни научить

ты можешь?

- нет

я в стихах специалист

52 
пиша в темноте

не заметил

что ручка не пишет

***

возможен ли стих

не содержащий

содержания слов

содержащихся в нем

?

$$
\text { *** }
$$

Гоголь

Достоевский

Толстои

Чехов

Горький тоже

но больше

в слаборазвитых странах 
выражая свое бессилие

изменить сложившуюся обстановку

вспомнИ Что то что

ты не можешь изменить

те6я не касается

а что тебя касается

ты уже меняешь

* * *

как человек

я не уверен

как позт

я не умею

***

а у тебя бывает

что никто за целыи день не позвонил

а ты сидишь один?

хорошо это или плохо?

54 
Ч То-то наивное

есть во всяком

сочетании слов

***

года три

мечтаешь о6 однои

потом как дурак

мечтаешь о другоп

$* * *$

у тебя сосед алкаш

ты его жалеешь

жалко я не төой сосед

мы бы поженились

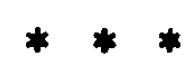

приятно заметить

столь нежное сердце 
в столь

B Takom

в общем

как вот Вы

***

какими

может быть

были

Te

от кого мы

может быть

произошли

происходит закат

происходит

исходит

уходит

уже происходит

He rak

He y Hac

a там

за кадром

56 
я спросил её

- а что мы теряем кроме своих цепеи?

она засмеялась

- приобретем же мы весь мир

она согласилась

$$
\text { * * * }
$$

она ли

давно ли

$$
* * *
$$

многие из тех

кто принимается грызть

гранит науки

останавливаются

на первых ступенях 
воевали мы кавказ

долго воевали

Лермон тов

Toricton

ну и получили

берию и джугашвили

Достоевскии

через каторгу

понял двадцатыи век

\section{Есенин}

покончил с собоя

ещё до коллективизации

$$
* * *
$$

нашлись сволочи

апеллировавшие к идиотам

58 
в нашей торьме

Они чувствуот себя

как дома

***

повинуясь порыву

повинуясь примеру

повинУЯсь

* * *

а начальство

всё ж милеe

всё ж румяней и белее

***

\section{а Они}

могут ли выразить

чем они лучше? 
смеясь над людьми

кого ты радуешь

***

совершенно верно

но зто общее суждение

а попробуи опровергни меня

в каждом частном случае

***

не безупречен

в том числе

и с этой точки

не понимая что устал

И что пора прерваться

он в внигу тупо продолжал

вперятья

* $\boldsymbol{A}$

60 
как все это грустно грустно

за окошком грязно грязно

город. тысяча проблем

я запутался совсем

* * *

ЛИЧно $Я$

ничуть не лучше

***

я подглядел что там внутри:

портрет Ленина

и надпись белым по красному

***

резче

и так тичнее 
жить в обществе

и быть свободным от него

нельзя

в особенности это относится

к социалистическому обществу

$$
\text { *** }
$$

жизнь

она того

любого достанет

***

Здесь в Козловском переулке

я не знал куда идти

повстречался мне прохожия

подсказал куда идти

проходя по переулку

снова вспомнил я его

62 


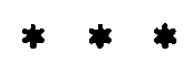

с кем ты

нe tyn

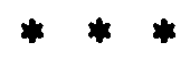

на выходе

мимо выхлопа

отвратительныезаведения

бесчеловечногоназначения

исоответствующеговида

***

Только и скажу

ч то есть такая местность

Кашёнкин Луг

- kak kak?

Кашёнкин Луг 
проезд автобусами

$215,259,637,24$

а также троллеибусами

9,36 и 73

солнышко

через стёклышко

* * *

для Бога

нас немного

пока народ его не знает

поэта нет

когда народ его узнает

поэта нет

***

неужели наша власть

наконец за ум взялась?

64 
погиб

но не обиделся

***

в те времена

думать / так/

было не принято

сеичас - непривычно

***

Сталин нетипичен

***

это стихотворение

передает не только состояние

но и устремление

***

ландыш

настоящ 


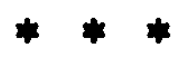

устал

как шакал

$\star * *$

обмен веществ

обман чувств

***

ОдИНочество

ОдИн ночь

$* * 4$

если 6 мы были рыбы

мы бы плавали

если 6 мы были птицы

мы бы летали

66 
но мы люди -

и мы валяемся в постели

***

муравьи-строители

и муравьи-мыслители

муравьи-строители

Инстинкту повИнуются

а муравьи-мыслители

с инстинктом соревнуются

$* * *$

все мы

под Богом ходим

в России живем

***

кто поможет мне выжить 
принимаем по внешности осуждаем по суиности

$$
\text { *** }
$$

Tot фakт

что зто был $я$

с трудом вмещается

в моём сознании

***

\section{выход}

конечно

всегда есть

но надоело

ero вcerдa

искать

$$
* * *
$$

1. чего же ты хочешь

2. чего то ведь надо

68 
одно другому мешает

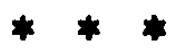

мы пали ниц

вы пали ницше

* *

читайте

но не завидуите

***

бандиты

и были среди них

более наивные

и менее наивные

и последние

победили

на этом закончился стих

69 
/как ты думаешь обо мне/

таких людеи не бывает

и $я$ не такои

$$
* * *
$$

наверно я

роман тизирую

романизируго

и романсизирую

наши отношения

как ты думаешь?

$$
* * *
$$

Конкретисты -

это Холин, Сапгир,

Некрасов, Сатуновскии

и Соковнин

с его предме тниками. 


\section{ARBEITEN UND TEXTE ZUR SLAVISTIK HERAUSGEGEBEN VON WOLFGANG KASACK}

1 Sabine Appel: Jurij Olesa. "Zavist" und "Zagovor Zuvstr". Ein Vergleich des Romans mit seiner dramatisierten Fassung. 1973. 234 S. DM 24.-

2 Renate Menge-Verbeeck: Nullsuffix und Nullsuffigierung im Russischen. Zur Theorie der Wortbildung. 1973. IV, 178 S. DM 18.-

3 Jozef Mistrik: Erakte Typologie von Texten. 1973. 157 S. DM 18.-

4 Andrea Hermann: Zum Deutschlandbild der nichtmarxistischen Sozialisten. Analyse der Zeitschrift "Russkoe Bogatstro" von 1880 bis 1904. 1974. 198 S. DM 20.-

5 Aleksandr Vredenskij: Izbrannoe. Herausgegeben und eingeleitet von Wolfgang Kasack. 1974. 116 S. DM 15.-

6 Volker Levin: Das Groteske in Michail Bulgakors Prosa mit einem Exkurs zu A. Sinjavskij. 1975. 158 S. vergriffen

7 Геннааий Айги: Стихи 1954-1971. РеАахция и вотупительная статья В. Kaзака. 1975. 214 S. vergriffon

8 Влааимир Казаков: Оиябха живых. Роман. 1976. 201 S. DM 20.-

9 Hans-Joachim Dreyer: Pëtr VerSigora. "Ljudi s cistoj sovest'ju". Veränderungen eines Partisanenromans unter dem EinfluB der Politik. 1976. 101 S. DM 15.-

10 Нихолай Эраман: Манаат. Пьеса в трех аействиях. Реаахция и вступительная статья В. Казаха. 1976. 109 S. DM 15.-

11 Karl-Dieter van Ackern: Bulat Okudzava und die kritische Literatur über den Krieg. 1976. 196 S. DM 20.-

12 Михаия Булгахов: Ранняя неизаанная проза. Составление и преАисловие Ф. Аевина. 1976. 215 S. DM 24.-

13 Eva-Marie Fiedler-Stolz: Ol'ga Bergol'c. Aspekte ihres lyrischen Werkes. 1977. 207 S. DM 20.-

14 Christine Scholle: Das Duell in der russischen Literatur. Wandlungen und Verfall eines Ritus. 1977. 194 S. DM 20.-

15 Aleksandr Vredenskij: Minin i Pozarskij. Herausgegeben von Felix Philipp Ingold. Vorwort von Bertram Müller. 1978. 49 S. vergr.

16 Irmgard Lorenz: Russische Jagdlerminologie. Analyse des Sprachgebrauchs der Jäger. 1978. 558 S. DM 60.-

17 Влааимир Казаков: Саучайный воин. Стихотворения 1961-1976. Позмы. Арамы. Очерк "Зуаескик". 1978. 214 S. vergriffen

München-Verlag OttoSagnerin Kommission 


\section{ARBEITEN UND TEXTE ZUR SLAVISTIK HERAUSGEGEBEN VON WOLFGANG KASACK}

18 Angela Martini: Erzähltechniken Leonid Nikolaevid Andreevs. 1978. 322 S. DM 30.-

19 Bertram Müller: Absurde Literatur in Rubland. Entstehung und Entwicklung. 1978. 210 S. DM 24.-

20 Михаил Булгахов: Ранняя несобранная проза. Составление $\Phi$. Аевина и А.В. Светина. Преаиоловие Ф. Аевина. 1978. $250 \mathrm{~S}$. DM 30.-

21 Die Russische Orthodore Kirche in der Gegenwart. Beiträge zu einem Symposium der Deutschen Gesellschaft für Osteuropakunde. Herausgegeben von Wolfgang Kasack. 1979. $86 \mathrm{~S}$. vergr.

22 Геортий Оболауев. Уотойчивое неравновооье. Стихи 1923-1949. Составление и поатотовха техста А.Н. Терезина. Преаноловие А.H Терезина. Поолесловие В. Казака. 1979. 176 S. DM 20.-

23 Wolfgang Kasack: Die russische Literatur 1945-1976. 1980. 72 S. vergriffen (siche ATS 28 und ATS 46)

24 Михаил Булгаков Ранняя неизвестная проза. Составмение и преаисловие Ф. Аевина. 1981. 254 S. DM 32.-

25 Позт-переводчик Константин Богатырев. Аруг немецкой Аитературы. Реаахтор-ооставитель Вольфганг Казак 0 участием Аьва Копелева и Ефима Эткинаа. 1982. 316 S. DM 34.-

26 Конотантин Вагинов: Собрание стихотворения. Составление. послесловие и примечания $\Lambda$. Черткова. Преаисловие В. Казака. 1982.240 S. DM 26.-

27 Михаил Булгахов Белая гвараия. Пьеса в четырех Аейотвиях. Вторая реаахция пьесы "Ани Турбиных". Поаготовка текста. преаисловие и примечания Аесли Миян. 1983. 152 S. DM 18.-

28 Wolfgang Kasack: Die russische Literatur 1945-1982. Mit einem Verzeichnis der Ubersetzungen ins Deutsche. 1983. 120 S. DM 15.-

29 Михаил Булгахов: Забытое. Ранняя проза. Составмение и преАисловие Ф. Аевина. 1983. 140 S. DM 18.-

30 Аев Аунц: Завешрние Царя. Неопубликованный хиносценарий. Расскази. Статьн. Рецензин. Письма. Нокрологи. Составиение и преАисловие Вольфганга Шриха. 1983. 214 S. DM 24.-

31 Lev Loseff: On the Beneficence of Censorship. Aesopian Language in Modern Russian Lilerature. 1984. 278 S. DM 38.-

Múnchen-Verlag Ottosagnerin Kommission 


\section{ARBEITEN UND TEXTE ZUR SLAVISTIK HERAUSGEGEBEN VON WOLFGANG KASACK}

32 Gernot Seide: Die Klöster der Russischen Orthodoxen Kirche im Ausland in Vergangenheit und Gegenwart. 1984. 196 S. vergriffen

33 Анарей Платонов: Старих и старуха. Потерянная проза. Составление и преАисловие Фолькера Аевина. 1984. 216 S. DM 26.-

34 Luise Wangler: Vasilij Belov. Menschliche und gesellschaftliche Probleme in seiner Prosa. 1985. 70 S. DM 12.-

35 Wolfgang Kasack: Russische Literatur des 20. Jahrhunderts in deutscher Sprache. 350 Kurzrezensionen von Ubersetzungen 1976-1983. 1985. 160 S. DM 22.-

36 Влааимир Аинаенберг (Челищев): Три Аома. Абтобиография 1912-1918 rг.. написанная в 1920 гоАу. ПоАГотовка текста и послесловие Вольфганга Казака. 1985. 92 S., 16 Abb. DM 16.-

37 Renate Schäper: Die Prosa V.G. Rasputins. Erzählverfahren und ethisch-religiöse Problematik. 1985. 294 S. DM 38.-

38 Wolfgang Kasack: Lexikon der russischen Literatur ab 1917. Ergänzungsband. 1986. 228 S. DM 22.-

39 Wolfgang Schriek: Ivan Smelev. Die religiöse Weltsicht und ihre dichterische Umsetzung. 1987. 321 S. 10 Abb. DM 38.-

40 Wolfgang Kasack: Bücher - Aufsätze - Rezensionen. Vollständige Bibliographie 1952-1987, anläblich des sechzigsten Geburtstages zusammengestellt von Irmgard Lorenz. 1987. $102 \mathrm{~S}$. DM 15.-

41 Barbara Göbler: A. Adamov und A. und G. Vajner. Aspekte des sowjetischen Kriminalromans. 1987. 104 S. DM 15.-

42 Fritz Wanner: Leserlenkung. Asthetik und Sinn in Dostoevskijs Roman "Die Brüder Karamazov". 1988. 274 S. DM 38.-

43 Frank Göbler: Vladislar F. Chodasevið. Dualität und Distanz als Grundzüge seiner Lyrik. 1988. 304 S. DM 38.-

44 Tausend Jahre Russische Orthodore Kirche. Beiträge von Geistlichen der Russischen Orthodoxen Kirche im Ausland und Wissenschaftlern verschiedener Disziplinen. Herausgegeben von Wolfgang Kasack. 1988. 200 S. DM 28.-

45 Die geistlichen Grundlagen der Ikone. Herausgegeben von Wolf8ang Kasack. 1989. 204 S.. 23 Abb. DM 28.-

46 Wolfgang Kasack: Russian literature 1945-1989. Translated by Carol Sandison. 1989.160 S, 35 Abs DM 24.-

München-Verlag OttoSagnerinKommission 


\section{ARBEITEN UND TEXTE ZUR SLAVISTIK SERAUSGEGEBEN VON WOLFGANG KASACK}

47 Иван Ахметьев Миниатюры. 1990. 76 S. DM 20.-

48 Christopher Hüllen: Der Tod im Werk Vladimir Nabokovs. Terra Incognita. 1990. 252 S. DM 38.München

München-Vorlag OttoSagnorin Kommission 